\title{
EXACERBATING EFFECT OF DIETARY 12-KETO OLEIC ACID ON VITAMIN E DEFICIENCY IN THE RAT ${ }^{1}$
}

\author{
Kenji Fukuzawa ${ }^{2}$ and Masao SAto $^{3}$ \\ ${ }^{2}$ Faculty of Pharmaceutical Science, University of Tokushima, Shomachi, Tokushima, Japan \\ ${ }^{3}$ The Central Laboratory, Fukushima Medical College, Sugitsumacho, Fukushima, Japan
}

\begin{abstract}
Summary 12-Keto oleic acid, possibly one of the oxidation products of long-chain, unsaturated fatty acids, was added to the feed of weanling male rats at the $1 \%$ level. Their growth curves, tissue weights, plasma alkaline phosphatase, GOT, and GPT activities, and plasma and liver lipid (cholesterol, triglyceride and phospholipid) levels were investigated and compared with those of weanlings fed a vitamin $\mathrm{E}$ deficient diet. Both the diet containing 12-keto oleic acid and the diet deficient in vitamin $\mathrm{E}$ decreased the growth rate of body weight and tissue weight, and increased the liver triglyceride and cholesterol levels. Parallel with these, increased hemolysis and stimulation of lipid peroxidation and fluorescent production in the liver homogenate were observed. Elevated plasma alkaline phosphatase and GOT activities which may be considered to be due to a functional disorder of the liver were also observed.
\end{abstract}

Because synthetic antioxidants prevent or diminish avitaminosis of $\mathrm{E}(1)$, while high levels of polyunsaturated fats promote it (2), autoxidized fats are considered a factor in the rate of incidence of $\mathrm{E}$ avitaminosis. Heat denaturation of unsaturated fatty acids is known to give rise to long-chain, keto-unsaturated acids $(3,4)$. KOKATNUR and his collaborators (5) found that the presence of small amounts of these long-chain keto fatty acids accelerated the development of encephalomalacia in chicks kept on a vitamin $\mathrm{E}$ deficient diet. Among the keto acids studied, 12-keto oleic acid (12-KOA) is the most potent one in this respect, and there is an interrelationship between the amount of this substance and the occurrence rate of the disease.

In this project the growth curves, organ weights, some plasma enzyme activities, and the plasma and liver lipid contents of rat weanlings were studied. One group of rats were given 12-KOA and the other group was fed a vitamin E

1 Presented at the 26th Annual Meeting of the Vitamin Society of Japan, May 22, 1974, Tokyo.

2 福沢健治, ${ }^{3}$ 佐藤政男 
deficient diet. In comparing the data from both groups, the interrelationship between 12-KOA and vitamin $\mathrm{E}$ deficiency is discussed.

\section{METHODS}

Materials. The preparation of 12-KOA has been described in the previous report (6).

Animals. Weanling male Wister rats were divided into four groups and fed either with standard laboratory chow (Oriental MF, Oriental Yeast Industrial Co., Tokyo; normal groups), with a vitamin $\mathrm{E}$ deficient diet, which was the same composition as described previously (7), or with these respective diets supplemented with $1 \%$ of $12-\mathrm{KOA}$. Food and water were offered ad libitum.

Chemical analysis. The total liver and plasma lipids were extracted with chloroform-MeOH (2:1). Triglyceride was separated by silicic acid column chromatography and determined colorimetrically according to SARDESAI and MANNING (8). Phospholipid phosphorus was measured by the procedure of BARTLETT (9). Cholesterol was determined by the Lieberman-Burchard reagent method of ONO (10).

Enzyme assay. The activities of GPT (plasma glutamic-pyruvic transaminase) and GOT (plasma glutamic-oxaloacetic transaminase) were determined by the method of ReITMAN and Frankel (11). Alkaline phosphatase activity was measured by the procedure of BESSEY et al. (12).

Estimation of lipid peroxidation. Lipid peroxidation was estimated by the same methods as described previously (7).

Fluorescence measurement. Two milliliters of incubation mixture were extracted twice with $4 \mathrm{ml}$ of spectral-graded chloroform-MeOH $(2: 1)$. The chloroform layer was separated and to this 0.1 volume of $\mathrm{MeOH}$ was further added to reduce the turbidity of this extract. The fluorometric measurement of this extract was done with Hitachi fluorescence spectrophotometer (MPF-2).

Hemolysis test. An adaptation of the method of Ikehata, and Sugryama (13) was used for the hemolysis studies. The red cell suspension $(2.5 \%)$ in salinephosphate buffer ( $\mathrm{pH} 7.4$ ) was incubated with $1 \% \mathrm{H}_{2} \mathrm{O}_{2}$ for 120 min at $37^{\circ} \mathrm{C}$. After centrifugation and dilution of the supernatant, the optical density of the latter was determined at $540 \mathrm{~nm}$. This value was compared with the value obtained for the sample not exposed to $\mathrm{H}_{2} \mathrm{O}_{2}$ and for the sample completely hemolyzed with distilled water.

\section{RESULTS AND DISCUSSION}

Compared with those rats on a normal diet, those on the vitamin E deficient diet showed slower growth. Addition of 12-KOA to these feeds further lessened the increase in body weight both in the normal rats and in the vitamin $\mathrm{E}$ deficient rats (Fig. 1). 


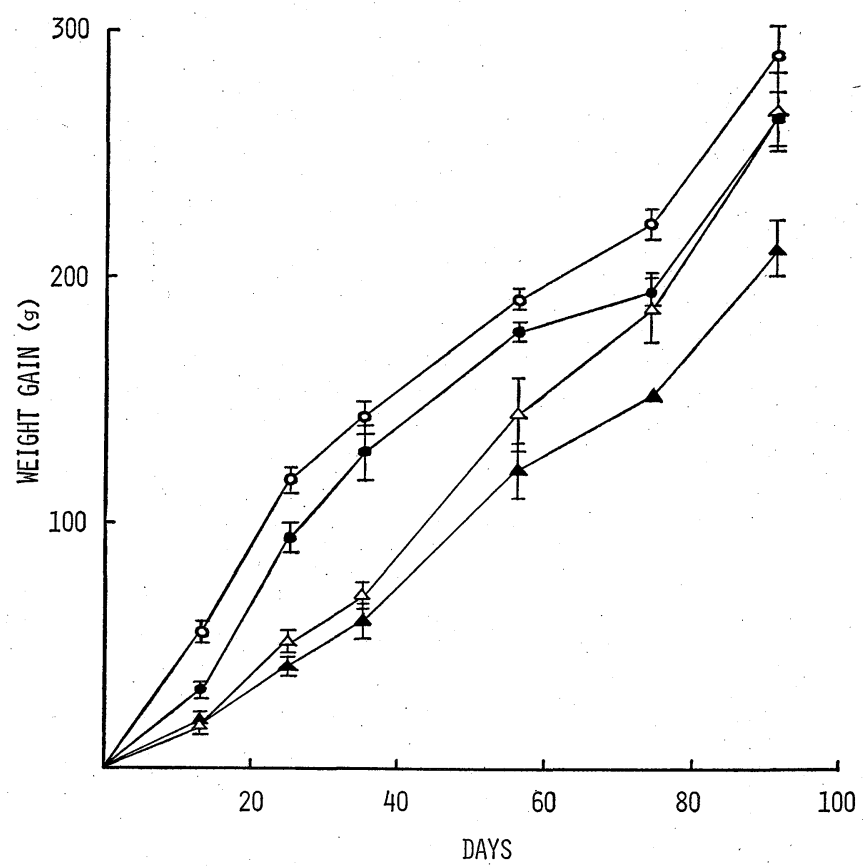

Fig. 1. Effect of dietary 12-KOA and vitamin $\mathrm{E}$ deficiency on growth. Normal (O), normal+12-KOA $(\bullet)$, E-deficient $(\triangle)$, E-deficient+12-KOA $(\Delta)$. Each column represents the average and standard error.

Table 1. Effect of dietary 12-keto oleic acid and vitamin E deficiency on changes in tissue weights.

\begin{tabular}{|c|c|c|c|c|c|c|c|}
\hline & & \multirow{2}{*}{$\begin{array}{c}\text { Weight } \\
\text { (g) }\end{array}$} & \multicolumn{2}{|c|}{ Liver weight } & \multicolumn{2}{|c|}{ Kidney weight } & \multirow{2}{*}{$\begin{array}{l}\text { Number } \\
\text { of } \\
\text { animals }\end{array}$} \\
\hline & & & (g) & $\begin{array}{l}\% \text { body } \\
\text { weight }\end{array}$ & $(\times 100 \mathrm{mg})$ & $\begin{array}{l}\% \text { body } \\
\text { weight }\end{array}$ & \\
\hline \multirow[t]{4}{*}{1 Week } & $\mathbf{N}$ & $82 \pm 3$ & $4.1 \pm 0.3$ & 5.0 & $10.0 \pm 0.4$ & 1.22 & 6 \\
\hline & NK & $73 \pm 3$ & $3.8 \pm 0.2$ & 5.2 & $8.3 \pm 0.4$ & 1.14 & 6 \\
\hline & $\mathrm{D}$ & $67 \pm 2$ & $3.4 \pm 0.1$ & 5.1 & $8.2 \pm 0.3$ & 1.22 & 6 \\
\hline & DK & $61 \pm 3$ & $2.9 \pm 0.8$ & 4.8 & $6.8 \pm 0.3$ & 1.12 & 6 \\
\hline \multirow[t]{4}{*}{5 Weeks } & $\mathbf{N}$ & $178 \pm 6$ & $7.2 \pm 0.3$ & 4.1 & $16.8 \pm 0.1$ & 0.94 & 6 \\
\hline & NK & $163 \pm 11$ & $6.7 \pm 0.6$ & 4.1 & $15.2 \pm 1.3$ & 0.93 & 5 \\
\hline & D & $112 \pm 5$ & $5.1 \pm 0.4$ & 4.5 & $10.1 \pm 0.3$ & 0.90 & 6 \\
\hline & DK & $102 \pm 7$ & $4.2 \pm 0.4$ & 4.1 & $9.6 \pm 0.5$ & 0.94 & 6 \\
\hline \multirow[t]{4}{*}{13 Weeks } & $\mathbf{N}$ & $326 \pm 13$ & $12.2 \pm 0.8$ & 3.7 & $25.2 \pm 1.0$ & 0.77 & 5 \\
\hline & NK & $301 \pm 12$ & $11.4 \pm 0.2$ & 3.8 & $23.8 \pm 1: 1$ & 0.79 & 5 \\
\hline & D & $310 \pm 16$ & $10.9 \pm 0.5$ & 3.5 & $22.3 \pm 1.2$ & 0.72 & 6 \\
\hline & DK & $254 \pm 12$ & $9.5 \pm 0.7$ & 3.7 & $17.7 \pm 1.1$ & 0.70 & 6 \\
\hline
\end{tabular}

$\mathrm{N}$ (normal), NK (normal+12-KOA), D (E-deficient), DK (E-deficient+12-KOA). 
The weight of the liver, kidney and spleen (data not shown) showed a similar trend to that of the body weight, i.e., the increase in weight was less in the vitamin $\mathrm{E}$ deficient rats than in the normal ones, and the addition of 12-KOA to these diets further lessened the weight increase of the organs (Table 1). However, their ratios to the body weight were almost constant in all four groups.

Table 2. Effect of dietary 12-keto oleic acid and vitamin E deficiency on plasma and hepatic lipid levels.

\begin{tabular}{|c|c|c|c|c|c|c|}
\hline & \multicolumn{3}{|c|}{ Liver } & \multicolumn{3}{|c|}{ Plasma } \\
\hline & $\begin{array}{c}\text { Triglyceride } \\
\text { ( } \mu \text { moles } / \\
10 \mathrm{~g})\end{array}$ & $\begin{array}{l}\text { Phospholipid } \\
\text { (mg of } \\
\text { P/100 g) }\end{array}$ & $\begin{array}{l}\text { Cholesterol } \\
(\mathrm{mg} / 100 \mathrm{~g})\end{array}$ & $\begin{array}{l}\text { Triglyceride } \\
(\mu \text { moles } / \mathrm{dl})\end{array}$ & $\begin{array}{l}\text { Phospholipid } \\
\text { (mg of } \mathrm{P} / \mathrm{dl} \text { ) }\end{array}$ & $\begin{array}{l}\text { Cholesterol } \\
\text { (mg/dl) }\end{array}$ \\
\hline Normal & $51 \pm 3(5)$ & $136 \pm 6(5)$ & $129 \pm 12(4)$ & $90 \pm 3(5)$ & $3.75 \pm 0.45(6)$ & $114 \pm 11(6)$ \\
\hline $\begin{array}{l}\text { Normal } \\
+12-K O A\end{array}$ & $98 \pm 18(4)$ & $146 \pm 11(4)$ & $163 \pm 18(4)$ & $114 \pm 20(6)$ & $4.38 \pm 0.39(6)$ & $113 \pm 14(6)$ \\
\hline E-deficient & $181 \pm 35(5)$ & $138 \pm 5(6)$ & $182 \pm 7(5)$ & $106 \pm 10(6)$ & $4.61 \pm 0.16(6)$ & $144 \pm 6(6)$ \\
\hline $\begin{array}{l}\text { E-deficient } \\
+12-\text { KOA }\end{array}$ & $185 \pm 5(5)$ & $141 \pm 8(6)$ & $213 \pm 5(4)$ & $97 \pm 21(6)$ & $5.16 \pm 0.17(6)$ & \\
\hline
\end{tabular}

Figures in brackets indicate the number of animals used.

Animals fed on their respective diets for 5 weeks. Values are mean \pm standard error.

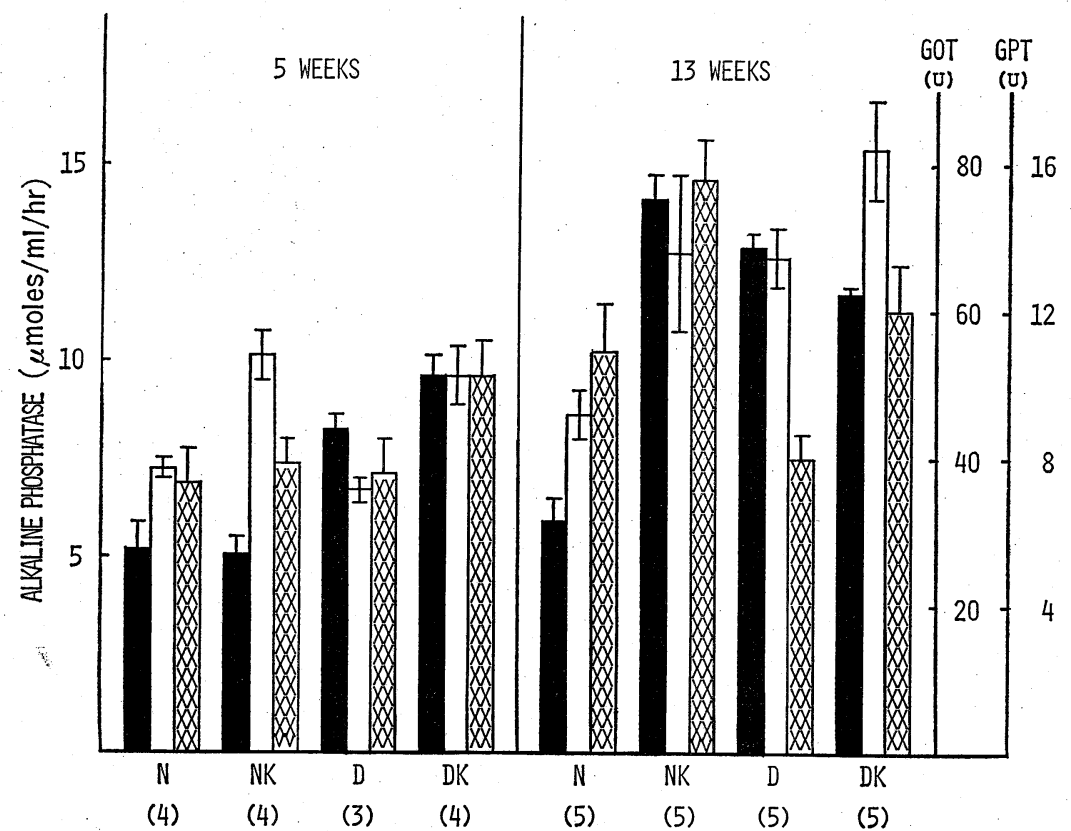

Fig. 2. Effect of dietary 12-KOA and vitamin E deficiency on the activities of plasma enzymes. Alkaline phosphatase (black bars), GOT (white bars), GPT (shaded bars). Normal (N), normal+12-KOA (NK), E-deficient (D), E-deficient+12-KOA (DK). Figures in brackets indicate the number of animals used. Each column represents the average and standard error. 
According to Hirayama and Hiroshige (14), vitamin E prevents the occurrence of ethanol-induced fatty liver and triglyceridemia. In the present study, we found that vitamin E deficiency or the administration of 12-KOA for five weeks caused a significant increase in the triglyceride level of the liver, but they did not affect its phospholipid level (Table 2). The cholesterol level of the liver was increased $40 \%$ and $60 \%$ on a diet containing 12-KOA and an Edeficient diet, respectively.

In the plasma, the situation was somewhat different: the triglyceride level was scarcely changed with the 12-KOA diet, the phospholipid tended to increase both with 12-KOA and the deprivation of vitamin $\mathrm{E}$, and the cholesterol level increased in the vitamin $\mathrm{E}$ deficient diet, but remained unchanged in 12-KOA feeding groups. CHEN et al. (15) also reported that the serum cholesterol level which is increased by a high protein diet falls when there is an increase of vitamin $\mathrm{E}$ content in the diet.

The above results suggest that 12-KOA accelerates the effect of vitamin $\mathrm{E}$ deficiency by intervening with some aspect of the fat metabolism.

According to KOSAKA et al. (16), the elevation of GOT and GPT activities in the serum of patients with liver diseases, e.g., chronic hepatitis and hepatocirrhosis, are effectively repressed with administration of vitamin E. As shown in

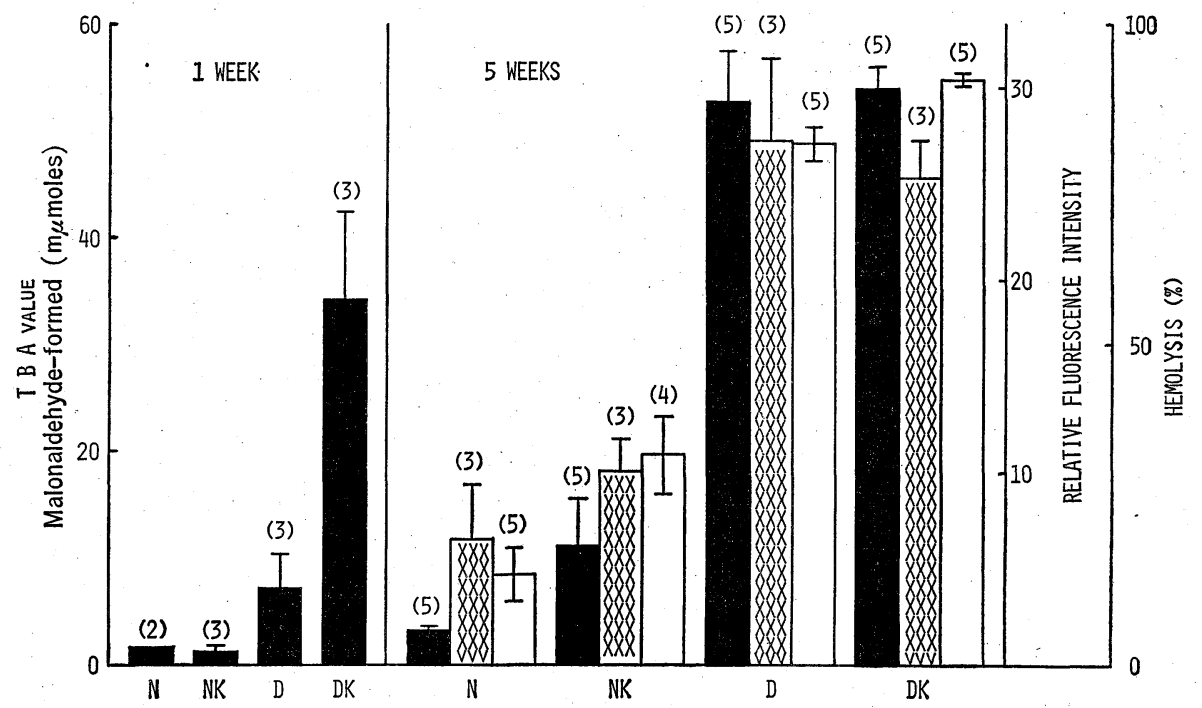

Fig. 3. Effect of dietary 12-KOA and vitamin E deficiency on the production of TBAreacting materials and fluorescence in rat liver homogenate. Two milliliters of liver homogenate $(10 \%)$ in $0.1 \mathrm{M}$ phosphate buffer $(\mathrm{pH} 6.0)$ were incubated at $37^{\circ} \mathrm{C}$ for $60 \mathrm{~min}$ (TBA-reactants) or $4 \mathrm{hr}$ (fluorescent products). TBA value (black bars), relative fluorescence intensity (shaded bars), hemolysis (white bars). Fluorescence intensity of $1 \mu \mathrm{g}$ quinine sulfate per milliliter of $0.1 \mathrm{~N} \mathrm{H}_{2} \mathrm{SO}_{4}$ set at 100 (EX set at 360 $\mathrm{nm}$, EM set at $430 \mathrm{~nm}$ ). Each column represents the average and standard error. Figin ures brackets indicate the number of animals used. 
Fig. 2, GOT activity rose following either vitamin $\mathrm{E}$ deprivation or the administration of 12-KOA for 13 weeks. GPT rose following 12-KOA treatment but was unaffected by the vitamin deprivation. Alkaline phosphatase was only slightly affected by either treatment for one week, but its activity rose two- to three-fold either with the vitamin deprivation for 5 or 13 weeks, or with the administration of 12-KOA for 13 weeks. These enzymes probably appear in the plasma following either necrosis of the liver cells or the increase of permeability of the cell membrane. The activity of $12-\mathrm{KOA}$ in accelerating the symptoms of vitamin $\mathrm{E}$ deficiency is also reflected in the change of activity of the plasma enzymes.

Hemolysis is one of the most common symptoms of vitamin $\mathrm{E}$ deficiency, even though it is not known whether it is of primary or secondary incidence. As shown in Fig. 3, addition of 12-KOA in normal diet was not so remarkable as due to deprivation of vitamin $\mathrm{E}$ but increased hemolysis. The TBA value was also increased with advancing vitamin E deficiency, and 12-KOA hastened its acceleration period. Production of fluorescent chromophores in five weeks showed the same change trend as hemolysis and TBA values.

Tappel speculated that lipid peroxidation elevation was the foremost process leading to appearance of the vitamin E deficiency symptoms (17). The above results may not establish that $12-\mathrm{KOA}$ is the primary cause of various symptoms of vitamin E deficiency, but it can be assumed to be one of the causes of certain symptoms of the deficiency, and if not the primary cause, then the secondary or the tertiary.

The authors wish to thank Dr. Mitsuru Uchiyama for his kind advice and Misses Mitsuru Ikeuchi and Yaeko Amō for their skillful technical assistance. Acknowledgements are also due to Eisai Co., Ltd. for a generous gift of vitamin $\mathrm{E}$ deficient diet.

\section{REFERENCES}

1) Fitch, C. D. and Dinning, J. S., J. Nutr., 79, 69 (1963).

2) Blaxter, K. L. and Brown, F., Nutr. Abstr. Revs., 22, 1 (1952).

3) Ellis, G. W., Biochem. J., 46, 129 (1950).

4) Artman, N. R. and Alexander, J. C., J. Am. Oil Chem. Soc., 45, 643 (1968).

5) Kokatnur, M. G., Okui, S., Kummerow, F. A., and Scott, H. M., Proc. Soc. Exptl. Biol. Med., 104, 170 (1960).

6) Sato, M. and Uchiyama, M., Chem. Pharm. Bull., 19, 1118 (1971).

7) Fukuzawa, K. and Uchiyama, M., J. Nutr. Sci. Vitaminol., 19, 433 (1973).

8) Sardesai, V. M. and Manning, J. A., Clin. Chem., 14, 156 (1968).

9) Bartlett, G. R., J. Biol. Chem., 234, 466 (1959).

10) Ono, T., Seikagaku (in Japanese), 38, 283 (1966).

11) Reitman, S. and Frankel, S., Am. J. Clin. Path., 28, 56 (1957).

12) Bessey, O. A., Lowry, O. H., and Brock, M. J., J. Biol. Chem., 164, 321 (1946).

13) Ikehata, H. and SugiYama, Y., Vitamins (Japan), 37, 31 (1968).

14) Hirayama, C. and Hiroshige, K., Experientia, 26, 1306 (1970).

15) Chen, L. H., LiaO, S., and PACKeTt, L. V., J. Nutr., 102, 729 (1972).

16) Kosaka, A., Kondo, T., TANi, M., and Tamura, H., Diagnosis and Treatment (Japan), 54, 177 (1966).

17) Tappel, A. L., Ann. N.Y. Acad. Sci., 203, 12 (1972). 